\title{
Residual analysis of selected pesticides in cucumber and spinach collected from local markets of Mymensingh sadar
}

\author{
MA Islam*, MZ Islam, MK Hossain
}

\author{
Department of Environmental Science, Faculty of Agriculture, Bangladesh Agricultural University, \\ Mymensingh-2202, Bangladesh
}

\begin{abstract}
To explore the chemical contamination of vegetables available in local market of Mymensingh this research work undertaken for detection and quantification of the presence of pesticides. Standard pesticides and GC (Gas Chromatography) were used to confirm their retention times and area of eluted peaks. By comparing the retention times of standards and samples, confirmation of residual presence of pesticides were studied. A result revealed that residue of a fungicide (Common Name: Mancozeb, a.i: Symoxanil 72 wp) was found in one Cucumber sample out of three where $50 \mathrm{ppm}$ quantified. On the other hand, out of 3 spinach samples, 1 of them showed presence of a insecticide (Common name: imidachloropid; a.i.: imidachloropid $20 \mathrm{SL}$ ) residues, which quantified as $35 \mathrm{ppm}$. Residual quantity determined in cucumber sample of BAUSesh More and spinach sample of Kewatkhali market, Mymensingh. To clarify the existing scenario in respect of all pesticide residues in vegetable sample, it would be necessary to develop all facilities for a modern analytical laboratories and skilled manpower. It may be useful for creating awareness about the available vegetables in consumers and farmers community.
\end{abstract}

Key words: Pesticide residues, vegetables, mancozeb, imidachloropid, GC

Progressive Agriculturists. All rights reserve

*Corresponding Author: maislam@bau.edu.bd

\section{Introduction}

Vegetables are important components of the human diet since they provide essential nutrients that are required for most of the reactions occurring in the body. Like other crops, fruits and vegetables are attacked by pests and diseases during production and storage leading to damages that reduce the quality and the yield. In order to reduce the loss and maintain the quality of fruits and vegetables harvest, pesticides are used together with other pest management techniques during cropping to destroy pests and prevent diseases. The use of pesticides has increased because they have rapid action, decrease toxins produced by food infecting organisms and are less labor intensive than other pest control methods (Gildenet al., 2010).

Among the vegetables, brinjal, cauliflower, tomato and okra etc. are some very common vegetables cultivated, throughout the country but all are badly affected by insect-pest and diseases. Brinjal (SolanummelongenaL.) suffers heavily at fruiting stage due to attack of shoot and fruit borers causing $70 \%$ damage to the crop and making it totally unfit for human (Misra and Sharma, 2007). Cauliflower (Brassica oleracea) also an important vegetable crop with an annual production of 3.39 million tones, is heavily attacked by various insects, resulting in severe loss of quality and production. Okra (AbelmoschusesculentusL.) is heavily infested by numerous insect pests for which different insecticides are used (Sinha and Sharma 2007).

In Bangladesh, the food production has been more than doubled since 1971, but the food security still 
remains a major development issue for its huge population (Weinberger and Genova, 2005). As the process of agricultural production is supported by the increasing use of agrochemicals and multiple cropping, the Government of Bangladesh has called for departure from rice-led production to a more diversified production base that includes several nonrice crops (Hoque, 2000). Diversification in vegetable crops and increasing commercialization can support the development of the agriculture sector in several ways. One potential drawback associated with a shift toward more intensive vegetable production is the reliance of most vegetable producers on heavy application of pesticide (Hossainet al., 2000).

The presence of pesticide residues is a concern for consumers because pesticides are known to have potential harmful effects to other non-targeted organisms than pests and diseases. The major concerns are their toxic effects such as interfering with the reproductive systems and fetal development as well as their capacity to cause cancer and asthma (Gildenet al., 2010). Most screening procedures in use today are capable of finding only a fraction of the pesticides that are registered around the world. GC provides the most comprehensive and reliable screening method available for pesticides, metabolites, and suspected endocrine disrupters. It has high sensitivity, a large linear response range, and low noise. It is also robust and easy to use, but it destroys the injected sample (Usher and Majors, 2003).

Different scientists (Karanth, 2000; Dasika et al., 2011; Hrouzkova and Matisova, 2011) analyzed pesticide residues in fruit and vegetables in India, Spain, China, Japan and other developed country. But limited pesticide residual analysis conducted by GC for available vegetables in Bangladesh (Sattar, 1985; Hossainet al., 2013). For the high sensitivity of chemicals GC technique is used for analyzing vegetables, available in local market of the study areas.

The present study was undertaken to explore the existing condition of available vegetables in local market and to know the types of pesticide which are used in vegetables and hence to determine residual levels of pesticide and the quantity of chemicals in vegetables.

\section{Materials and Methods}

Samples were collected from 3 sites of Mymensingh Sadar Upazila: a) Kewatkhali market, b) $B A U K R$ market and c) Seshmore, BAU.Two available vegetables (Spinach and Cucumber) were collected randomly on July 17' 2013. The collected vegetable samples were immediately taken into the laboratory of the Department of Environmental Science, Bangladesh Agricultural University and cut into small pieces with proper labeling. The labeled samples were kept in deep freezer $\left(-20^{\circ} \mathrm{C}\right)$. About 2 gm of each sample (frozen part) was grinded by hand grinder then allowed in $5 \mathrm{ml} \mathrm{Hx}$ (n-Hexane) containing test tube for 15 minutes. To avoid the evaporation of solvents and volatile chemicals from the samples, the mouth of the test tube was tightly closed by cork. After 15 minutes, each part was mixed well by 2 minutes hand shaking and keeps 5 minutes for stabling. The supernatant solution ( $\mathrm{Hx}$ with extracted compound) was collected by small pipette carefully and collected the solution in vial. The method of sample extraction (liquid extraction technique) was followed by two research reports (Usher and Majors, 2003; Fernandes et al., 2011) with modification (changing of extraction time, shaking manually instead of mechanical shaker, only one solvent used etc.).

The analytical analysis was carried out with Gas Chromatograph (GC) [GC-2014] Shimadzu Corporation, Kyoto, Japan. DFID detector was used in this experiment. The overall GC condition is tabulated below (Table 1). Injection of each standard solution was repeated several times (at least 5 times) for the confirmation of the respective retention time. Table 2 indicates the different concentration of both standard solutions were injected in GC system under above mentioned condition and made calibration curve. By comparing the retention time and area of the standard solution and studied samples, it was matched both and confirmed then calculated the GC eluted compound. By plotting the area of a specific peak at a specific retention time in the calibration 
Table 1. Conditions and different parameters of Gas Chromatography (GC)

\begin{tabular}{|c|c|c|}
\hline & GC/DFID & Stability/Reproducibility \\
\hline Column & $\begin{array}{l}\text { RT-Mseive 5A, serial number: } 1104596 \text {. Length: } 30 \mathrm{~m} \text {, } \\
\text { Inner diameter: } 0.53 \mathrm{~mm} \text {, } \\
\text { Film thickness: } 50.00 \mathrm{um} .\end{array}$ & $\begin{array}{l}\text { Column flow: } 6.63 \mathrm{~mL} / \mathrm{min} \\
\text { Maximum temperature: } 300^{\circ} \mathrm{C} \text {. }\end{array}$ \\
\hline Oven & $\begin{array}{l}50^{\circ} \mathrm{C}(3 \mathrm{~min}) \text {, to } 200^{\circ} \mathrm{C} \text { at } 10^{\circ} \mathrm{C} / \mathrm{min} \text {, to } 300^{\circ} \mathrm{C} \text { at } \\
15^{\circ} \mathrm{C} / \mathrm{min} \text { and hold finally } 5 \mathrm{~min} \text {. (For Mancozeb) } \\
60^{\circ} \mathrm{C}\left(5 \mathrm{~min} \text { ), to } 180^{\circ} \mathrm{C} \text { at } 10^{\circ} \mathrm{C} / \mathrm{min} \text {, to } 280^{\circ} \mathrm{C} \text { at }\right. \\
10^{\circ} \mathrm{C} / \mathrm{min} \text { and hold finally } 8 \mathrm{~min} \text {. (For Imidachloropid) }\end{array}$ & $\begin{array}{l}\text { Column oven: } 50^{\circ} \mathrm{C} \text { (for } \\
\text { Mancozeb), } 60^{\circ} \mathrm{C} \text { (for } \\
\text { Imidachloropid), }\end{array}$ \\
\hline Carrier & Hydrogen (30 mL/min), Air (142.1 mL/min) & Hydrogen $(30 \mathrm{ml} / \mathrm{min})$, \\
\hline Detection & DFID, $300^{\circ} \mathrm{C}$, Sampling rate: $40 \mathrm{msec}$. & DFID, $300^{\circ} \mathrm{C}$ \\
\hline Injection & $1 \mu \mathrm{L}$, Direct injection, $200^{\circ} \mathrm{C}$ & Split \\
\hline Linear velocity & $60.7 \mathrm{~cm} / \mathrm{sec}$ & Pressure: $66.8 \mathrm{kPa}$ \\
\hline Purge Flow & $3.0 \mathrm{~mL} / \mathrm{min}$ & Split ratio: 20 \\
\hline
\end{tabular}

Table 2. Information on different standard chemicals used in analysis

\begin{tabular}{|c|c|c|c|}
\hline Item & Common Name & Active ingredient & Source of chemical \\
\hline Fungicide & Mancozeb & Symoxanil 72 wp & $\begin{array}{c}\text { Z.H. Scientific and Chemicals } \\
\text { Mart, Dhaka, Bangladesh }\end{array}$ \\
\hline Insecticide & Imidachloropid & Imidachloropid 20 SL & . \\
\hline
\end{tabular}

\section{Results and Discussion}

This study was performed by collecting samples of vegetables (Spinach and Cucumber) from different markets of Mymensingh. Since all the pesticide were not used on all the vegetables, therefore the study of only those pesticide was carried out on different vegetables which were applied on them in the field. The vegetable samples had pesticidal contamination of Mancozeb in Cocumber (VC1) and Imidachloprid in Spinach (VS3) which were collected respectively from Shesmore and Kewatkhali market.

The experimental work was conducted by using only n-Hexane for extraction purposes. For this reason, there were no remarkable gas chromatograms produced after analysis. For the extraction procedure, lack of time and lack of chemical availabilities, this research based on only liquid extraction (using nHexane). Fernandes et al. (2011) reported the pesticide residues in vegetables for the several extraction procedures (liquid extraction, single drop microextraction, microwave-assisted extraction, pressurized liquid extraction, supercritical fluid extraction, solid-phase extraction, solid-phase microextraction, matrix solid-phase dispersion, and stir bar sorptive extraction).

\section{Calibration of Mancozeb solution}

The different concentrations of standard solutions (Mancozeb) were eluded at 14.52 minutes. During making a calibration curve with the standard solutions areas of peaks for every concentration were calculated. Figure 1 showed that single peak for a normal standard straight line was drawn using Mancozeb content and peak areas from which acalibration curve was made for the measurement of different concentration of pesticides which were used in vegetables. 


\section{Calibration of Imidachloprid solution}

Figure 2 indicated the different concentrations of standard imidachloprid solutions were observed at 19.20 minutes and calibration curves prepared by using those data. During making a calibration curve with the standard solutions, areas of peaks for every concentration were calculated. Figure 2 showed the calibration curve on the relationship between concentration of imidachloprid and peak area $\left(10^{5}\right)$.

The peak area of the specific amount of a chemical varied with the nature, elution and characteristic of chemicals studied. There was enormous peak area differences found in respect of specific amount of standard chemicals. Few researchers (Hossainet al., 2000; Akan et al., 2013; Butler et al., 2013) suggested the similar variation among the different chemicals occurred in their peak areas in GC analysis.

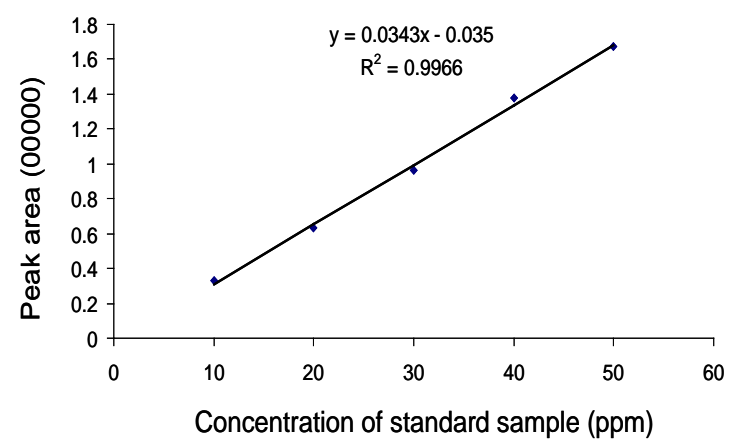

Figure 1. Calibration curve of different concentrations of standard Mancozeb

\section{Chromatograms of Mancozeb (64\%) + Symoxanil (8\%) solution}

In GC analysis, Mancozeb (64\%) + Symoxanil (8\%) solution was showed the response at 14.52 minutes, which was repeated several times (at least 5 times). According to figure 3 , the eluted retention time was fixed at 14.52 minutes then researcher confirmed about the peak.

When the extracted samples were injected in the analytical tools (GC) then most of the samples did not show such reasonable peaks. Figure 4 showed that there was no such response observed due to absence of such analytical compounds in the samples or any other difficulties occurred during the process from sampling to analysis.

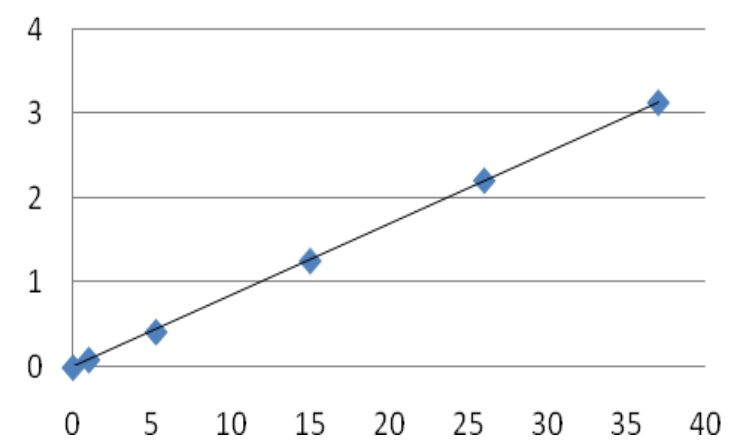

Figure 2. Calibration curve of different concentrations of standard imidachloprid. $\mathrm{X}$ axis denotes concentration of standard in ppm, and $\mathrm{Y}$ axis denotes peak area $\left(10^{5}\right)$

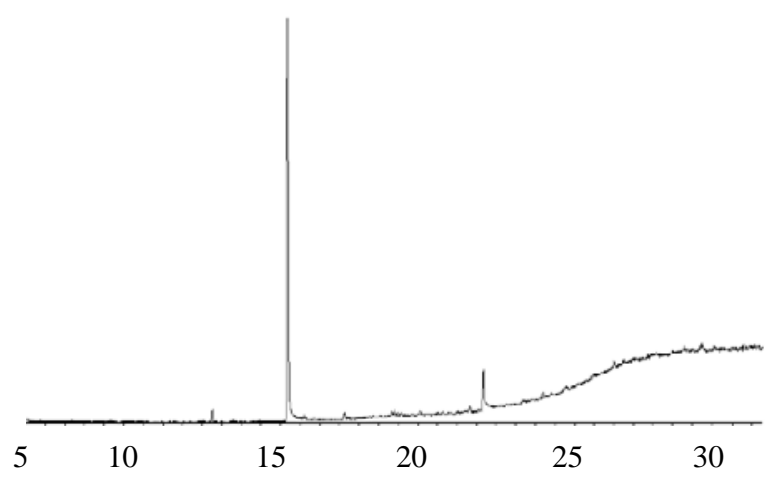

Figure 3. Chromatograms eluted by GC for standard solution. One major eluted peak showed Mancozeb elution. Numbers in $\mathrm{X}$ - axis indicate retention time in minutes.

But, one extracted sample (code name: VC1, Cucumber from BAU Seshmore) eluted many peaks within 4 to 28 minutes. Figure 3 and 4 showed that the elucidated peaks and their retention times were compared with standard data, where 14.52 minute elucidated compound found. This sample was injected repeatedly 3 times more to confirm the similarity of the elucidated peaks as well as to confirm the retention time. Figure 4 revealed the peak responded at 14.52 minutes which occurred due to the presence of Mancozeb in that sample. 


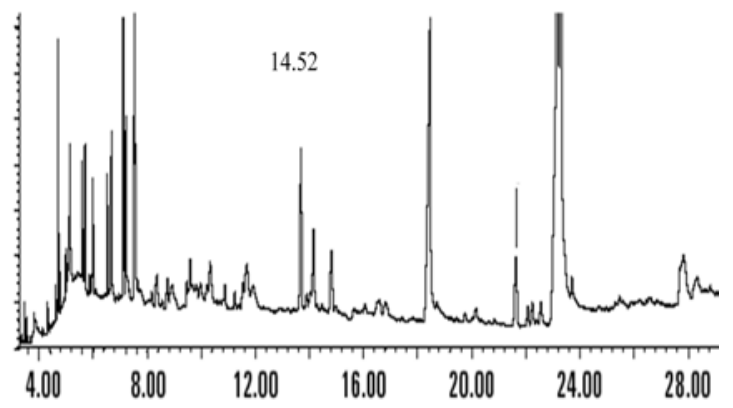

Figure 4. Natural samples of cucurbits (VC1) eluted Mancozeb and other unknown peaks

\section{Chromatograms of imidachloprid solution}

In another sample of vegetables (VS3, Spinach from KewatkhaliMarket) showed a minute response like imidachloprid at 19.20 minutes which might be identical with previously obtained results. Figure 5 and 6 indicated that there were many unknown compounds elucidated in both analysis, which might be the compounds containing in that vegetables or other foreign substance (pesticides, other metabolites etc.). Figure 6 illustrated many natural compound or unknown compounds was appeared after gas chromatography analysis.

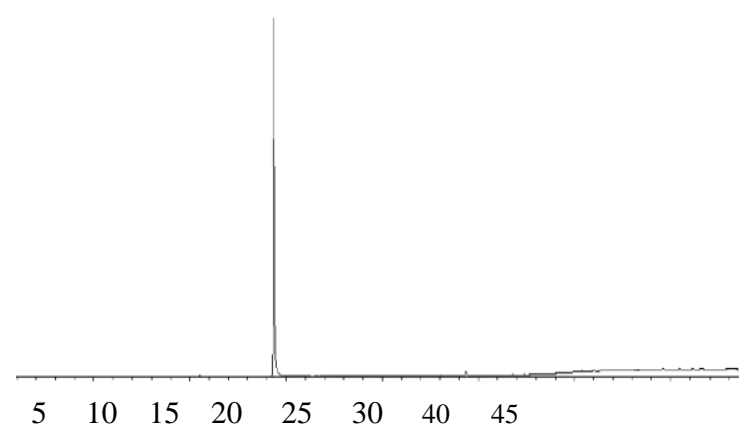

Figure 5. Chromatograms eluted by GC for standard solution. One major eluted peak showed imidachloprid elution. Numbers in $\mathrm{X}$ - axis indicate retention time in minutes

\section{Quantification of pesticide residues}

By comparing with the area of known standard chemicals of a specific retention time and an unknown concentrated peak, the quantity was determined. The calibration curve of the standard known sample was helpful to determine the unknown concentration. By plotting the area of eluted peak the quantity of analyzed compound was calculated easily.

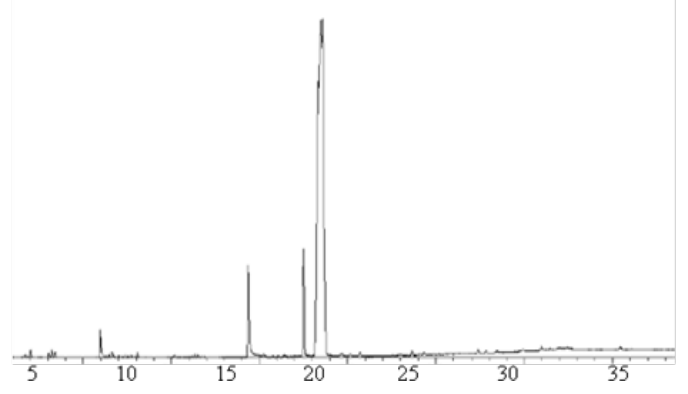

Figure 6. Chromatogram showing spinach sample (VS3) eluted imidachloprid active ingredient at $19.20 \mathrm{~min}$ (Numbers in Xaxis indicate retention time in minutes).

Figure 4 described about the peak area (VC1, 167000) of a specific retention time in the respective standard solution curve (calibration curve), about 50 ppm concentration of Mancozeb recorded. Figure 6 also showed the spinach samples were contained imidachloprid occurred in one sample (VS3,) with remarkable amount (35ppm) as the area was 318000 . The above data showed that vegetables sample was collected from different sites were contaminated with above mentioned chemicals but some site samples had no detectable residues. Out of 6 samples 4 samples (66\%) were free from pesticide residues and rest of the samples (34\%) contained pesticide residues. The results of the study revealed that the $34 \%$ of total analyzed samples were contaminated with different pesticide residues.

Out of three samples of cucumber only 1 sample was contained Mancozeb residue. In cucumber sample VC1 (Collected from BAUseshmore) the residue of Mancozeb was found in the concentration approximately of $50 \mathrm{ppm}$. In Cucumber sample VC2 and VC3 (collected from BAUKR market and Kewatkhali Bazar) the Mancozeb residue was not found. In the sample of cucumber it might contain other pesticide residue but in this study no detection was found due to lack of standard pesticides.

In spinach, out of three samples only one sample found to be contaminated with pesticide. In spinach sample VS3 (Collected from Kewatkhali bazar) the 
residue of imidachloprid was found in the concentration approximately of 35ppm. Other spinach sample VS1 and VS2 (Collected from BAU Seshmore and KR market, BAU) the imidachloprid residue was not found. Pesticide residue of Dichlorovs, Diazinon, Chlopyrifos and Fenitrithion in root sample of spinach ranged from 10.11-116.05 ppm, in stem of spinach 15.34-150.05 ppm and in leaf sample 18.93-176.56 ppm (Akan et al., 2013). They detected higher concentration of residue in leaf sample of spinach and lower in root sample.

\section{Conclusion}

Results revealed that only 2 samples (out of 6 samples) responded to chemical elusions. Several peaks were eluted after the injection of extracted sample in GC. Retention time of eluted peak was compared to standard solution peak to identify chemical. In Cucumber sample (VC1) one peak is found which is similar to Mancozeb peak. The quantity of the Mancozeb residue in that sample was about 50 ppm using peak area in standard calibration curve. In spinach sample out of 3 samples only one shows the presence of chemical residue. In cucumber sample (VS3), one peak was identified as imidachloprid peak. The imidachloprid residue was quantified and recorded as approximately 35ppm. Chemical residues were not found in other 4 sample due to different possible reason such as study area variation, differences of extraction procedure, variation of sampling portion of vegetables, variation of GC analytical conditions and limitation of availability of standard solution and solvents.

Results indicated that about one third of the vegetable samples contained harmful pesticide residues, which consumed by human being. Further research works would be necessary to explore the existing residual level of different pesticides among the vegetables marketed in Bangladesh. The awareness of farmers, consumers, scientists and extension personnel would be emphasized through this result.

\section{References}

Akan JC, Jafiya L, Mohammed Z, Rahman FA (2013). Organophosphorus pesticide residues in vegetables and soil samples from alau dam and gongulong agricultural areas, Borno State, Nigeria.International Journal of Environmental Monitoring and Analysis,1(2): 58-64.

Butler J, Steiniger D, Phillips E (2008). Analysis of pesticide residues in lettuce using a modified quechers extraction technique and single quadrupole GC/MS [Online], Available via: www.thermo.com. (Accessed 12 November 2013).

Dasika R, Tangirala S, Naishadham P (2011). Pesticide residue analysis of fruits and vegetables.J. Environ. Chem. Ecotoxicol.,4(2): 19-28.

Fernandes VC, Valentina F, Domingues VF, Mateus N, Matos CD (2011). Determination of Pesticides in Fruit and Fruit Juices by Chromatographic Methods: An Overview. Journal of Chromatographic Sci.,vol: 49.

Gilden RC, Huffling K, Sattler B (2010). Pesticides and Health Risks.JOGNN, 39: 103-110.

Hoque ME (2000). Crop diversification in Bangladesh.Papdemetrioii MK and Dent FJ (eds.), Crop diversification in the AsiaPacific region, Bangkok, Thailand: Food and Agriculture Organization of the United Nations.

Hossain MI, Shively G, Mahmoud C (2000). Pesticide expenditure in a rice vegetable farming system: Evidence from Lowincome Farms in Bangladesh. IPM-CRSP Working Paper, P. 120.

Hossain SM, Hossain MA, Rahman MA (2013). Health Risk Assessment of Pesticide Residues via Dietary Intake of Market Vegetables from Dhaka, Bangladesh. Bangladesh j. pestici. Sci. and Environ.,21(7):54-58.

Hrouzkova S, Matisova E (2011). Fast gas chromatography and its use in pesticide residues analysis [Online], Available via: www.intechopen.com. (Accessed 12 November 2013).

Karanth NGK (2000). Challenges of Limiting Pesticide Residues in Fresh Vegetables: The Indian Experience Proceedings of the 
International Workshop. Montpellier, pp. 113.

Misra PN Singh MP (1996). Chemical control of okra in the Terai region Uttar Pradesh.Indian J. Ent, 45(2): 152-158.

Sattar MA (1985). Improved analysis of phenoxy herbicides in soils by internal standard method by using a gas chromatography.Bangladesh j. pestici. Sci. and Environ.,1: 20-29.

Sinha SR Sharma PK (2007). Efficacy of neonicotinoids against okra insect pest.Pesticide Res. J.,19(1): 42-44.
Ushers K, Majors RE (2003). Analysis of pesticide residue in apple by GC using agilent bond [Online], Available via: www.agilent.com. (Accessed 16th November 2013).

Weinberger K, Genova CA (2005). Vegetable production in Bangladesh: commercialization and rural livelihood. Technical Bulletin No 33.Shanhua, Taiwan: AVRDC-The World Vegetable Center, 5(21): 605-621. 